\title{
DOES PREOPERATIVE ANXIETY AFFECT EARLY OUTCOMES OF OPEN-HEART SURGERY?
}

\author{
Zeki Talas ${ }^{1}$, Muhip Kankoํㅗㄱ, Şadan Yavuz Prof ${ }^{1}$, Sibel Gür ${ }^{1}$, Burhan Küçük ${ }^{1}$, and Tülay \\ Çardaközü ${ }^{1}$
}

${ }^{1}$ Kocaeli Universitesi Tip Fakultesi

October 20, 2021

\begin{abstract}
Aim: We aim to determine the preoperative anxiety levels of patients with open-heart surgery and examine the relationship between anxiety levels and postoperative complications. Material and Methods: In our prospective study, 200 patients who will undergo open-heart surgery preoperative anxiety levels were measured using the Hamilton anxiety scale (HAM-A). Anxiety levels and the development of complications were investigated. Results: Preoperative anxiety was more common in females $(\mathrm{p}=0.001)$. The length of stay in the intensive care unit $(\mathrm{p}=0.006)$ and the hospital stay $(\mathrm{p}=0.005)$ were found to be longer in patients with high anxiety. It was observed that high preoperative anxiety severity increased the risk of developing postoperative complications $(\mathrm{p}=0.000024)$. Conclusion: We can say that preoperative anxiety, which is not considered very important, is seen more frequently than expected for patients who will undergo open-heart surgery. In our study, it was observed that high anxiety levels increased the risk of postoperative complications.
\end{abstract}

\section{Hosted file}

Anxiety and cardiac surgery.docx available at https://authorea.com/users/442083/articles/ 542442-does-preoperative-anxiety-affect-early-outcomes-of-open-heart-surgery 


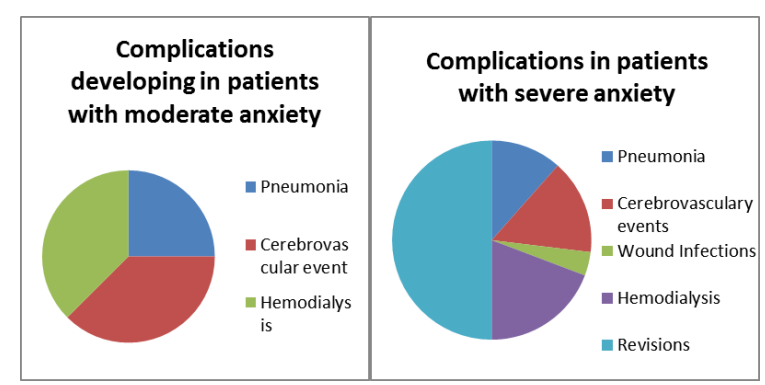

\section{Hosted file}

HAM-A table.docx available at https://authorea.com/users/442083/articles/542442-doespreoperative-anxiety-affect-early-outcomes-of-open-heart-surgery 